\title{
Design and Fabrication of motorized automated Object lifting jack
}

\author{
Ivan Sunit Rout ${ }^{1}$, Dipti Ranjan Patra ${ }^{1}$, Sidhartha Sankar Padhi ${ }^{1}$, \\ Jitendra Narayan Biswal ${ }^{1}$, Tushar Kanti Panda ${ }^{1}$ \\ I'Assistant Professor, Department of Mechanical Engineering, C.V.Raman College of Engineering, \\ Bhubaneswar, India)
}

\begin{abstract}
With the increasing levels of technology, the efforts are being put to produce any kind of work that has been continuously decreasing. The efforts required in achieving the desired output can be effectively and economically be decreased by the implementation of better designs. Power screws are used to convert rotary motion into reciprocating motion. An object lifting jack is an example of a power screw in which a small force applied in a horizontal plane is used to raise or lower a large load. In this fabricated model, an electric motor will be integrated with the object lifting jack and the electricity needed for the operation will be taken from the d.c battery and thereby the mechanical advantage will be increased.
\end{abstract}

Keywords: - Object lifting jack, automation, limit switch, lead screw

\section{INTRODUCTION}

Our research survey in this regard revealed that in several automobile garages, revealed the facts that mostly some difficult methods were adopted in lifting the vehicles for reconditioning, repair and maintenance. This fabricated model has mainly concentrated on this difficulty, and hence a suitable device has been designed, such that the vehicle and heavy objects can be lifted from floor land without the application of impact force. The fabrication part of it has been considered with almost case for its simplicity and economy, such that this can be accommodated as one of its essential tools on automobile garages. The object lifting jack has been developed to cater to the needs of small and medium automobile garages, which are normally man powered with minimum skilled labour. In most of the garages the vehicles are lifted by using screw jack. This needs high man power and skilled labour. In order to avoid all such disadvantages, the automated motorized object lifting jack has been designed in such a way that it can be used to lift the vehicle very smoothly without any impact force. The operation is made simple so that even unskilled labour can use it with ease. The d.c motor is coupled with the lead screw by gear arrangement, the lead screw rotation depends upon the rotation of d.c motor. This is an era of automation where it is broadly defined as replacement of manual effort by mechanical power in all degrees of automation. The operation remains to be an essential part of the system although with changing demands on physical input, the degree of mechanization is increased.

\subsection{Need for automation}

- To achieve mass production.

- To reduce human effort.

- To increase the efficiency of the jack.

- To reduce the work load.

- To reduce the production cost.

- To reduce the production time.

- To reduce the material handling.

- To reduce the fatigue of workers.

\subsection{Principle of operation}

The lead screw is considered as an inclined plane with inclination $\alpha$. When the load is being raised or lowered, following forces act at a point on this inclined plane.

1.2.1 Load (W): It always acts in vertically downward direction.

1.2.2 Normal reaction $(\mathrm{N})$ : It acts perpendicular (normal) to the inclined plane.

1.2.3 Frictional force $(\mu \mathrm{N})$ : It acts opposite to the motion. When the load is moving the inclined plane, frictional force acts along the inclined plane in downward direction and when the load is moving down the inclined plane, frictional force acts along the inclined plane in upward direction. 
1.2.4 Effort(P): It acts in a direction perpendicular to the load (W). It may act towards right to overcome the friction and raise the load.

When load is raised,

For an equilibrium of horizontal forces, $\mathrm{P}=\mu \mathrm{N} \cos \alpha+\mathrm{N} \sin \alpha \quad \ldots .(1)$

For an equilibrium of vertical forces, $\quad \mathrm{W}=\mathrm{N} \cos \alpha-\mu \mathrm{N} \sin \alpha \quad \ldots .(2)$

Dividing equation (1) by (2) we get,

$\mathrm{P}=\mathrm{W}(\mu \cos \alpha+\sin \alpha)$

$\cos \alpha-\mu \sin \alpha$

The coefficient of friction $\mu$ is expressed as $\mu=\tan \theta$

Substituting equation (4) in (3) we get,

$\mathrm{P}=\mathrm{W} \tan (\theta+\alpha)$

The torque $\mathrm{T}$ required to raise the load is given by, $\mathrm{T}=\tan (\theta+\alpha)$

When load is lowered,

For an equilibrium of horizontal forces, $\mathrm{P}=\mu \mathrm{N} \cos \alpha-\mathrm{N} \sin \alpha$

For an equilibrium of vertical forces, $\quad \mathrm{W}=\mathrm{N} \cos \alpha+\mu \mathrm{N} \sin \alpha$

Dividing equation (7) by (8) we get,

$\mathrm{P}=\mathrm{W}(\mu \cos \alpha-\sin \alpha)$

$\cos \alpha+\mu \sin \alpha$

Substituting equation (4) in (9) we get,

$\mathrm{P}=\mathrm{W} \tan (\theta-\alpha)$

The torque $\mathrm{T}$ required to raise the load is given by, $\mathrm{T}=\tan (\theta-\alpha)$

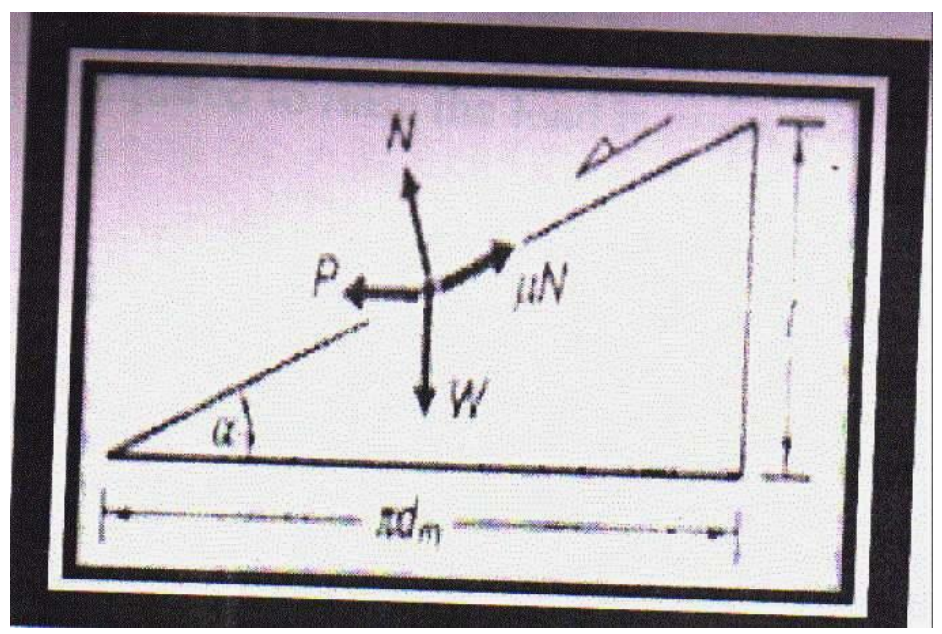

Fig 1: Forces acting in an inclined plane

\subsection{Components of fabricated model}

The main parts of the automated motorized object lifting jack are as follows:

\subsubsection{D.C motor}

An electric motor is a machine which converts electrical energy into mechanical energy. Its action is based on the principle that when a current carrying conductor is placed on a magnetic field, it experiences a magnetic force whose direction is given by Fleming's left hand rule. When a motor is in operation, it develops torque. This torque can produce mechanical rotation. D.C motors are also like generators classified into shunt wound or series wound or compound wound motors.

\subsubsection{Lead Screw}

A lead screw is a portable device consisting of s screw mechanism used to raise or lower the load. The lead screw can be short, tall, fat or thin depending on the amount of pressure they will be under and space that they need to fit into. It is made of various types of metals but the screw itself is made of lead. A large amount of heat is generated in it and long lifts can cause serious overheating. To retain the efficiency, it must be used under ambient temperatures, otherwise lubricants must be applied. These are oil lubricants intended to enhance the equipment's capabilities. Apart from proper maintenance, to optimize the capability and usefulness of lead screw it is imperative to employ it according to its design and construction.

\subsubsection{Batteries}


In isolated systems away from the grid, batteries are used for storage of excess solar energy which can be converted into electrical energy. In fact for small units with output less than one kilowatt, batteries seem to be less the only technically and economically available storage means. Since both the photovoltaic system and batteries are high in capital costs, it is necessary that the overall system be optimized with respect to available energy and local demand pattern.

\subsubsection{Ball bearing}

This is a type of rolling element bearing that uses balls to maintain the separation between the bearing races. The purpose of a ball bearing is to reduce rotational friction and support and radial and axial loads. It achieves this by using atleast two races to contain the balls and transmit the loads through the balls.

\subsubsection{Spur gears}

These are designed to transmit motion and power between parallel shafts which are the most economical gears in the power transmission industry. Two types are used in this model:

\subsubsection{Internal spur gear}

These spur gears are turned inside out. In other words, the teeth are cut into the inside diameter while the outside diameter is kept smooth. This design allows for the driving pinion to rotate internal to the gear, which, in turn, allows for clean operation. Intended for light duty applications, these are gears always available only in brass. When choosing a mating spur gear always remember that the difference in the number of teeth between the internal gear and pinion should not be less than 12 or 15 .

\subsubsection{External spur gear}

Perhaps the most often used and simplest gear system, external spur gears are cylindrical gears with straight teeth parallel to the axis. They are used to transmit rotary motion between parallel shafts and the shafts that rotate in opposite directions. They tend to be noisy at high speeds as the two gear surfaces come into contact at once.

\subsubsection{Limit Switch}

It is a switch operated by the motion of a machine part or presence of an object. It is used for control of a machine, as safety interlocks, or to count objects passing a point. It is a electromechanical device that consists of an actuator mechanically linked to a set of contacts. When an object comes into contact with the actuator, the device operates the contacts to make or break an electrical connection. It is used in a variety of applications and environments because of their ruggedness, ease of installation, and reliability of operation. It can determine the presence or absence, passing, positioning and end of travel of an object. It was first used to define the limit of travel of an object, hence the name 'limit switch.'

\subsubsection{Control switch}

It is used in order to start or stop the entire operation of the object lifting jack. The type of switch that is used is known as a toggle switch. The toggle switch is a class of electrical switches that are manually actuated by a mechanical lever, handle, or rocking mechanism.. This is designed to provide the simultaneous actuation of multiple sets of electrical contacts, or the control of large amounts of electric current or mains voltages.

\subsubsection{Control cables}

These are used in order to connect the battery to the motor and the switch.

\subsubsection{Base and Frame}

A base for the entire set-up has also been made. The motor is mounted on an inverted U shaped support frame. Ball rollers are attached to four ends of the base for movement and are electrically controlled by switch.

\subsection{Specification of parts}

\subsubsection{D.C motor}

\begin{tabular}{|l|l|}
\hline \multicolumn{1}{|c|}{ Torque } & $10 \mathrm{Kg} \mathrm{cm}$ \\
\hline Speed & $150 \mathrm{rpm}$ \\
\hline Voltage supply & $12 \mathrm{~V}$ \\
\hline Type & D.C \\
\hline
\end{tabular}

\subsubsection{Larger Gear}

\begin{tabular}{|l|l|}
\hline Addendum circle diameter & $73.45 \mathrm{~mm}$ \\
\hline Dedendum circle diameter & $61.80 \mathrm{~mm}$ \\
\hline Larger width of tooth & $5.46 \mathrm{~mm}$ \\
\hline Smaller width of tooth & $1.44 \mathrm{~mm}$ \\
\hline Depth of cut & $6.45 \mathrm{~mm}$ \\
\hline Thickness & $12.95 \mathrm{~mm}$ \\
\hline
\end{tabular}

\subsubsection{Lead Screw}

\begin{tabular}{|l|l|}
\hline \multicolumn{1}{|c|}{ Outer diameter $\left(\mathrm{d}_{\mathrm{o}}\right)$} & $13.7 \mathrm{~mm}$ \\
\hline Inner diameter $\left(\mathrm{d}_{\mathrm{i}}\right)$ & $11 \mathrm{~mm}$ \\
\hline Mean diameter $(\mathrm{d})$ & $12.7 \mathrm{~mm}$ \\
\hline Pitch & $2 \mathrm{~mm}$ \\
\hline
\end{tabular}

1.4.4 Smaller Gear

\begin{tabular}{|l|l|}
\hline Addendum circle diameter & $44.95 \mathrm{~mm}$ \\
\hline Dedendum circle diameter & $32.52 \mathrm{~mm}$ \\
\hline Larger width of tooth & $4.76 \mathrm{~mm}$ \\
\hline Smaller width of tooth & $1.14 \mathrm{~mm}$ \\
\hline Thickness & $13.06 \mathrm{~mm}$ \\
\hline
\end{tabular}




\subsubsection{Roller}

\begin{tabular}{|l|l|}
\hline Torque & $5 \mathrm{Kg} \mathrm{cm}$ \\
\hline Speed & $150 \mathrm{rpm}$ \\
\hline Voltage supply & $12 \mathrm{~V}$ \\
\hline Type & D.C \\
\hline Number & 2 \\
\hline
\end{tabular}

\subsubsection{Base}

\begin{tabular}{|l|l|}
\hline Length & $72.5 \mathrm{~mm}$ \\
\hline Breadth & $42.5 \mathrm{~mm}$ \\
\hline Thickness & $2 \mathrm{~cm}$ \\
\hline Material used & Plywood \\
\hline
\end{tabular}

\subsubsection{Limit Switch}

\begin{tabular}{|l|l|}
\hline Number & 2 \\
\hline Type & Roller type \\
\hline Two way voltage supply & $12 \mathrm{~V}$ \\
\hline
\end{tabular}

\subsubsection{Control Switch}

\begin{tabular}{|c|l|}
\hline Type & DPCO ( Double Pole Control Off) \\
\hline
\end{tabular}

\subsubsection{Load Panel}

\begin{tabular}{|l|l|}
\hline Diameter & $9.8 \mathrm{~cm}$ \\
\hline Thickness & $5 \mathrm{~mm}$ \\
\hline
\end{tabular}

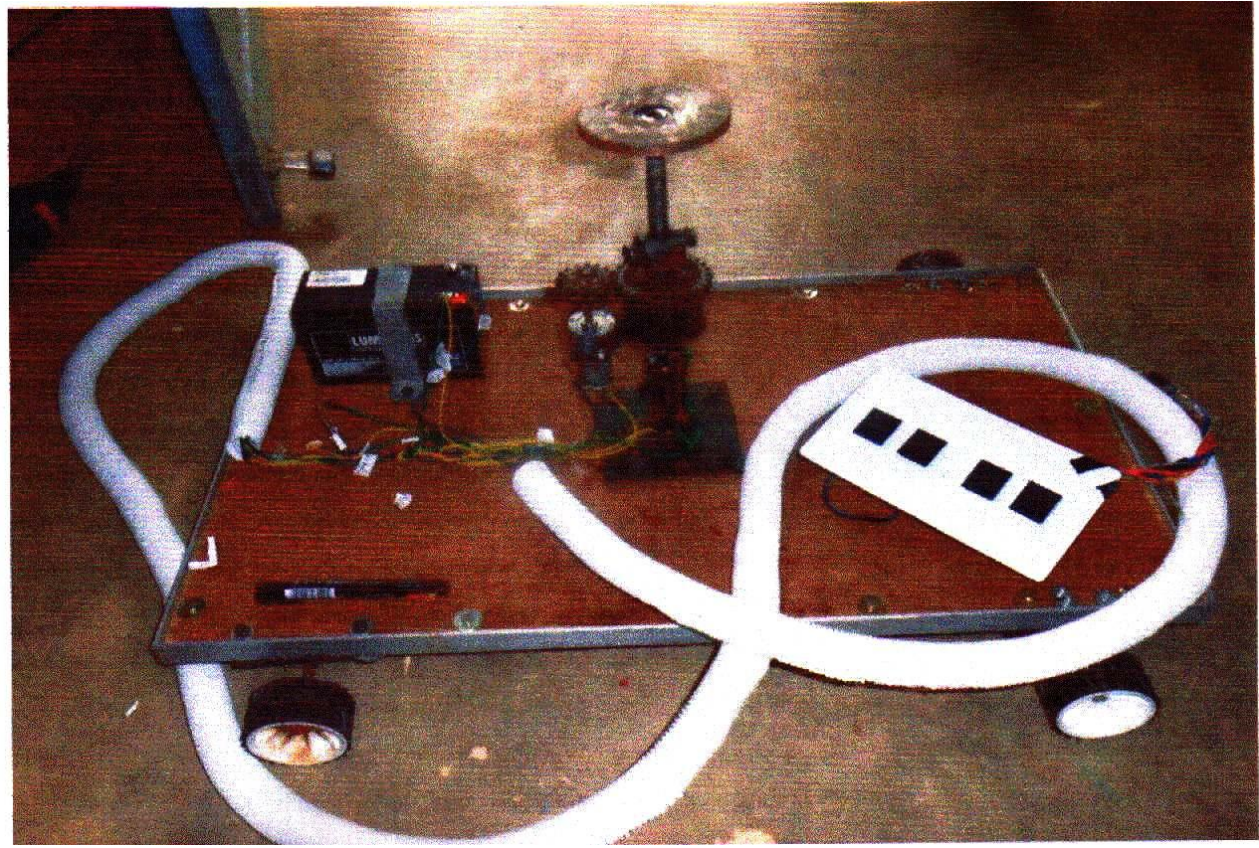

Fig 2: Fabricated model of Object lifting jack

\section{DESIGN CONSIDERATIONS}

The load on the screw is the load which is to be lifted $\mathrm{W}$, twisting moment $\mathrm{M}$, between the screw threads and force $\mathrm{F}$ at the handle to rotate the screw. The load $\mathrm{W}$ is compressive in nature and induces the compressive stress in the screw. It may also lead the screw to buckle. The load F produces bending and it is maximum, when the screw is at its maximum lift. The screw also experiences twisting moment due to $\mathrm{F}$, the shear stress is also induced in the screw due to the twisting moment between the threads of screw and nut.

Step I Problem Specification

It is required to design an object lifting jack for supporting the machine parts during their repair and maintenance. It should be a general purpose jack with a load carrying capacity of $50 \mathrm{KN}$ and a maximum lifting height of $0.3 \mathrm{~m}$. The jack is so operated by means of a D.C motor.

Step II Selection of Materials

(i) The frame of the object lifting jack has complex shape. It is subjected to compressive stress. Grey cast iron is selected as the material for the frame. Cast iron is cheap and it can be given any complex shape without involving costly machining operations. Cast iron has higher compressive strength compared with steel. Therefore, it is technically and economically advantageous to use cast iron for the frame. 
(ii) The screw is subjected to torsional moment, compressive force and bending moment. From strength consideration, EN8 is selected as material for screw.

(iii) There is a relative motion between the screw and the nut, which results in friction. The friction causes wear at the contacting surfaces. When the same material is used for these two components, the surfaces of both components get worn out, requiring replacement. This is undesirable. The size and shape of the screw make it costly compared with the nut. The material used for the nut is stainless steel.

\section{Step III Design of object lifting jack}

The object lifting jack is an intermittently use device and wear of threads is not an important consideration. Therefore, instead of trapezoidal threads, the screw is provided with square threads. Square threads have higher efficiency and provision can be made for self-locking arrangement. When the condition of self-locking is fulfilled, the load itself will not turn the screw and descend down, unless an effort in the reverse direction is applied.

\section{Observed data:}

\section{CALCULATIONS}

Nominal diameter of screw, $\mathrm{d}=13.7 \mathrm{~mm}$

Core diameter of screw, $\mathrm{d}_{\mathrm{c}}=11 \mathrm{~mm}$

Pitch of screw thread, $\mathrm{p}=2 \mathrm{~mm}$

Load $\mathrm{W}=20 \mathrm{~kg}$

Coefficient of friction, $\mu=0.15$

Mean diameter of screw, $\mathrm{d}_{\mathrm{m}}=12.7 \mathrm{~mm}$

Helix angle of screw, $\alpha=2.68^{0}$

Tangential force required at the circumference of the screw to raise the load $\mu=\tan \emptyset=0.15$

$\mathrm{p}=\mathrm{W} \times \underline{\tan \alpha+\tan \varnothing}=40.2 \mathrm{~N}$

$1-\tan \alpha \cdot \tan \varnothing$

Torque required to operate the screw $=\mathrm{p} \times \underline{\mathrm{d}}+\mu \mathrm{r}_{\mathrm{m}}$

$$
\begin{aligned}
& =40.2 \times(12.7 / 2)+(0.15 \times 200 \times 18) \\
& =825.27 \mathrm{~N} \mathrm{~mm}=0.8257 \mathrm{Nm}=8.5 \mathrm{Kg} \mathrm{cm}
\end{aligned}
$$

Efficiency of the screw $=\mathrm{T}_{0} / \mathrm{T}_{1}$

$$
=\frac{200 \times(12.7 / 2)}{0.15 \times 200 \times 18+200 \times(12.7 / 2)}=27 \%
$$

For lowering load $(\mathrm{P})=\mathrm{W} \tan (\alpha+\varnothing)$

$$
=\mathrm{W} \times \underline{\tan \alpha+\tan \varnothing}=19.826 \mathrm{~N}
$$

$1-\tan \alpha \cdot \tan \varnothing$

Torque $=\mathrm{p} \times \underline{\mathrm{d}}+\mu \mathrm{r}_{\mathrm{m}} \mathrm{W}=0.662 \mathrm{~N}$

2

Shear stress due to torque $\mathrm{T}_{1}, \tau=16 \mathrm{~T}_{1} / \pi\left(\mathrm{d}_{\mathrm{c}}\right)^{3}=825.27 \mathrm{~N} / \mathrm{mm}^{2}=3.15 \mathrm{~N} / \mathrm{mm}^{2}$

Compressive stress due to axial load $\left(\sigma_{\mathrm{c}}\right)=\mathrm{W} / \mathrm{A}=2.10 \mathrm{~N} / \mathrm{mm}$

Shear stress due to torque $\left(\sigma_{\mathrm{c} \text { max }}\right)=0.5\left[\sigma_{\mathrm{c}}+\sqrt{\sigma_{\mathrm{c}}^{2}+4 \tau^{2}}=4.5 \mathrm{~N} / \mathrm{mm}^{2}<50 \mathrm{~N} / \mathrm{mm}^{2}\right.$

Maximum shear stress $=3.32 \mathrm{~N} / \mathrm{mm}^{2}<40 \mathrm{~N} / \mathrm{mm}^{2}$

So, design is safe.

$$
\begin{aligned}
& \text { Spur Gear, } \\
& \text { Gear Ratio }=1.75 \\
& \mathrm{~T}_{\mathrm{p}}=16 \quad \mathrm{~T}_{\mathrm{g}}=28 \\
& \text { Velocity ratio }=0.571 \\
& \mathrm{~N}_{\mathrm{p}}=150 \quad \mathrm{~N}_{\mathrm{g}}=85.714 \\
& \mathrm{~A}_{\mathrm{p}}=44.95 \quad \mathrm{~A}_{\mathrm{g}}=73.45 \\
& \mathrm{D}_{\mathrm{p}}=32.96 \quad \mathrm{D}_{\mathrm{g}}=61.80 \\
& \mathrm{Y}=0.175-0.841 / \text { no. of teeth }
\end{aligned}
$$

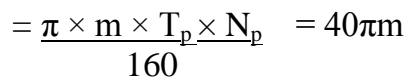




$$
\begin{aligned}
& \mathrm{C}_{\mathrm{v}}=\frac{3}{3+\mathrm{v}}=\frac{3}{3+0.12566}=0.959 \\
& \mathrm{Y}_{\mathrm{p}}=0.175-\frac{0.84}{16}=0.1224 \\
& \mathrm{Y}_{\mathrm{g}}=0.1449 \\
& \mathrm{~W}_{\mathrm{t}}=\sigma_{\mathrm{wp}} \times \mathrm{b} \times \pi \times \mathrm{m} \times \mathrm{Y}_{\mathrm{p}} \\
& \underline{15.40}=60 \times 6 \times \pi \times 0.097 \times \frac{3}{3+0.12566}
\end{aligned}
$$$$
46.2+1.93424=96.4521 \mathrm{~m}^{3}
$$$$
\mathrm{m}=2.5 \text { standard }
$$

Addendum $=3.45 \mathrm{~mm}$

Dedendum $=8.2 \mathrm{~mm}$

Centre distance between the shaft $=55 \mathrm{~mm}$

Wear tooth load $\left(\mathrm{W}_{\mathrm{w}}\right)=\mathrm{D}_{\mathrm{p}} \times \mathrm{b} \times \mathrm{Q} \times \mathrm{K}$

$$
\begin{aligned}
& =40 \times 12.5 \times(14 / 11) \times 1.57 \\
& =1000 \mathrm{~N}
\end{aligned}
$$

Dynamic Load $\left(\mathrm{W}_{\mathrm{d}}\right)=\mathrm{W}_{\mathrm{t}}+\mathrm{W}_{\mathrm{t}}$

$$
=\frac{21 \mathrm{v}\left(\mathrm{b}_{\mathrm{c}}+\mathrm{W}_{\mathrm{t}}\right)}{21 \mathrm{v}+\sqrt{\mathrm{b}_{\mathrm{c}}+\mathrm{W}_{\mathrm{t}}}}=43.3 \mathrm{~N}
$$

$\mathrm{V}=0.341 \mathrm{~m} / \mathrm{s}$

$\mathrm{b}=12.5 \mathrm{~mm}$

$\mathrm{C}=\frac{\mathrm{K}_{e}}{1+1}=1063.4$

$$
\overline{\frac{1}{\mathrm{E}_{\mathrm{p}}}+\frac{1}{\mathrm{E}_{\mathrm{g}}}}
$$

$\mathrm{W}_{\mathrm{d}}=825.4 \mathrm{~N}$

Since $\mathrm{W}_{\mathrm{d}}<\mathrm{W}_{\mathrm{w}}$. Design is true.

$\mathrm{W}_{\mathrm{s}}=\sigma_{\mathrm{c}} \times \mathrm{b} \times \mathrm{P}_{\mathrm{c}} \times \mathrm{y}$

$\sigma_{\mathrm{c}}=80 \mathrm{~N} / \mathrm{mm}^{2}$

$\mathrm{b}=12.5 \mathrm{~mm}$

$\mathrm{P}=\pi \mathrm{m}$

$\mathrm{Y}=0.1224$

$\mathrm{W}_{\mathrm{s}}=958.185$

$\mathrm{W}_{\mathrm{s}}>\mathrm{W}_{\mathrm{D}}$

It is true.

\section{WORKING MECHANISM}

STEP 1 The lead acid battery is used to drive the d.c motor. The d.c motor shaft is connected to the spur gear. If power is driven to the d.c motor, it will run so that the spur gear also runs to slow down the speed of the d.c motor. The object moving jack moves the lead screw upwards, so that the vehicle lifts from the ground. The vehicle is lifted by using the lifting platform at the top of the jack. The motor draws power supply from the battery. The lifting and uplifting is done by changing the battery supply to the motor.

STEP 2 After pressing the DPCO switch, the circuit is completed and from battery power is transferred to the motor that is connected to the roller. Now the roller starts moving. Now controlling the two number of DPCO switch which is connected to the two motors at the base the whole set-up is adjusted below the body which is being lifted.

STEP 3 Now pressing the DPCO switch to the circuit which is connected to the motor that is coupled to the lead screw, the circuit is completed and voltage from the battery is pass to the motor. When tapping the switch to the positive pole, positive voltage is supplied to the d.c motor moves in clockwise direction and lead screw moves in downward direction.

STEP 4 When tapping the switch to the negative pole, negative voltage is supplied to the d.c motor moves in anticlockwise direction and lead screw moves in upward direction.

STEP 5 Now when the lead screw moves to the maximum limit, the limit switch at the upper end gets activated and the circuit gets cut-off. When the lead screw moves to the minimum limit, the limit switch at the bottom end gets activated and the circuit gets cut-off. 


\section{CONCLUSION}

Object lifting jacks are the ideal product to push, pull, lift, lower and position loads of anything from a couple of kilograms to hundreds of tonnes. The need has long existed for an improved portable jack for automotive vehicles. it is highly desirable that a jack become available that can be operated alternatively from inside the vehicle or from a location of safety off the road on which the vehicle is located. Such a jack should be light enough and be compact enough so that it can be stored in an automobile trunk, can be lifted up and carried by most adults to its position of use, and yet be capable of lifting a wheel of a 4000-5000 pound vehicle off the ground. Further, it should be stable and easily controllable by a switch so that jacking can be done from a position of safety. It should be easily movable either to a position underneath the axle of the vehicle or some other reinforced support surface designed to be engaged by a jack. Thus, the product has been developed considering all the above requirements. This particular design of motorized automated object lifting jack will prove to be beneficial in lifting and lowering of heavy loads.

\section{REFERENCES}

[1] M.M. Noor, K. Kadirgama and M.M. Rahman, Analysis Of Auto Car Jack, National Conference in Mechanical Engineering Research and Postgraduate Students, FKM Conference Hall, UMP, Kuantan, Pahang, Malaysia, 26-27 May 2010, 198-203.

[2] Mohd Abuzaid, Mohd Hasnain, Shabaj Alam, Sohail Khan and Surendra Agarwal, Inbuilt Hydraulic jack in Automobile vehicles, International Journal of Innovations in Engineering and Technology, 2(2),2013,76-84.

[3] Tarachand G. Lokhande, Ashwin S. Chatpalliwar and Amar A. Bhoyar, Optimizing Efficiency of Square Threaded Mechanical Screw Jack by Varying Helix Angle, International Journal of Modern Engineering Research,.2(1), 2012, 504-508.

[4] P.S. Rana, P.H. Belge, N.A. Nagrare, C.A. Padwad, P.R. Daga, K.B. Deshbhratar and N.K. Mandavgade, European Journal of Applied Engineering and Scientific Research, 1 (4), 2012,167-172.

[5] Prashant Kumar Srivastav, Vipin Kumar Pandey, Shailesh Kumar Maurya, Ajit Tiwari, Jawed Rafiq and S.K. Dwivedi, Highly Efficient Motorized Screw Jack, International Journal of Computational Engineering Research, 3(5), 2013, 35-41.

[6] A. S. Akinwonmi and A. Mohammed, Modification of the Existing Design of a Car Jack, Journal of Emerging Trends in Engineering and Applied Sciences, 3 (4), 2012, 581-588.

[7] J.J. Ferreira, M.G. Boocock and M.I. Gray, Review of the risks associated with pushing and pulling heavy loads (Health and Safety Laboratory Broad Lane Sheffield S3 7HQ, 2004). 